\section{Original Article}

Korean J Transplant 2020;34:185-192 https://doi.org/10.4285/kjt.2020.34.3.185
Received June 17, 2020

Revised August 6, 2020

Accepted September 7, 2020

Corresponding author: Hyo Chae Paik Department of Thoracic and

Cardiovascular Surgery, Severance Hospital, Yonsei University College of Medicine, 50-1 Yonsei-ro, Seodaemun-gu, Seoul 03722, Korea

Tel: +82-2-2228-2145

Fax: +82-2-393-6012

E-mail: HCPAIK@yuhs.ac

(C) The Korean Society for Transplantation This is an Open Access article distributed under the terms of the Creative Commons Attribution Non-Commercial License (http://creativecommons.org/licenses/ by-nc/4.0/) which permits unrestricted non-commercial use, distribution, and reproduction in any medium, provided the original work is properly cited.

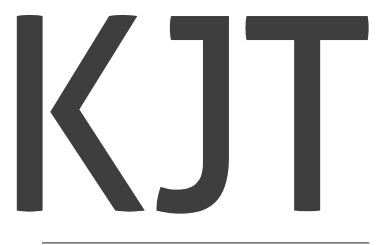

pISSN 2671-8790

elSSN 2671-8804

\title{
Impact of extended-criteria donor lungs according to preoperative recipient status and age in lung transplantation
}

\author{
Jee Won Suh ${ }^{1}$, Jin Gu Lee ${ }^{2}$, Moo Suk Park ${ }^{3}$, Song Yee Kim³ ${ }^{3}$ Su Jin Jeong ${ }^{4}$, \\ Hyo Chae Paik ${ }^{2}$
${ }^{1}$ Department of Thoracic and Cardiovascular Surgery, Yongin Severance Hospital, Yonsei University College of Medicine, Yongin, Korea
${ }^{2}$ Department of Thoracic and Cardiovascular Surgery, Severance Hospital, Yonsei University College of Medicine, Seoul, Korea Medicine, Seoul, Korea
${ }^{4}$ Division of Infectious disease, Department of Internal Medicine, Severance Hospital, Yonsei University College of Medicine, Seoul, Korea \\ ${ }^{3}$ Division of Pulmonology, Department of Internal Medicine, Severance Hospital, Yonsei University College of
}

Background: Organ donor shortage remains as one of the limiting factors for lung transplantation. Given the increase in waiting time, preoperative condition has worsened and affects surgical outcomes. This study aimed to evaluate the immediate postoperative and long-term outcomes of lung transplantation in extended-criteria donor (ECD) lungs compared with standard-criteria donor (SCD) lungs.

Methods: A total of 246 patients who had undergone double-lung transplantation during the study period were enrolled. SCD was defined based on the following characteristics: age $<55$ years, $<20$ pack-years smoking history, and $\mathrm{PaO}_{2} /$ fraction of $\mathrm{O}_{2}$ ratio $>300$ $\mathrm{mmHg}$. Organ donors who do not fulfill these criteria were classified as ECD. Pre- and postoperative data for outcomes and survival data were analyzed.

Results: ECD showed significant association with extracorporeal membrane oxygenation weaning in the operating room (hazard ratio [HR], 0.531; 95\% confidence interval [Cl], 0.291-0.970; $\mathrm{P}=0.039)$ considering recipient's age and status at operation. The ECD group showed comparable survival rate with the SCD group (HR, 1.413; 95\% Cl, 0.8852.255; $P=0.148)$, with adjustment of other factors. However, when the recipient had Korean Network for Organ Sharing (KONOS) status 0 at the time of transplantation (HR, 1.662; $95 \% \mathrm{Cl}, 1.025-2.568 ; \mathrm{P}=0.039), \mathrm{G} 3$ primary graft dysfunction at 72 hours after surgery (HR, 2.508; 95\% Cl, 1.416-4.440; $\mathrm{P}=0.002$ ) was a risk factor that decreased survival.

Conclusions: The outcome of ECD is not inferior to that of SCD. Therefore, ECD lung should be considered a potential donor organ following active donor management rather than a contraindication of transplantation in highly selected recipients.

Keywords: Lung transplantation; Donor; Extended criteria donor 


\section{HIGHLIGHTS}

- Extended-criteria donor (ECD) lungs are not inferior to standard-criteria donor lungs.

- Recipient characteristics such as preoperative Korean Network for Organ Sharing (KONOS) status 0 have a more important effect on patient's outcome.

- ECD lungs did not affect G3 primary graft dysfunction at 72 hours after transplant.

\section{INTRODUCTION}

Lung transplantation is the only treatment option for patients with end-stage lung disease. Organ donor shortage remains as one of the limiting factors for the widespread usage of lung transplantation. This shortage of organ donors is due to the low rate of organ donations from brain dead donors (BDDs) and the low procurement rate of lungs. In Korea, organ donation from BDDs was low at 1.78 per million population $(20.5 \%, 92 / 449)$; in truth, only 92 of the 255 patients who waited for lung transplantation had undergone lung transplantation in 2018 [1]. Given the increase in the waiting time caused by the shortage of donated organs, the numbers of waiting-list patients who required hospital admission and who required extracorporeal membrane oxygenation (ECMO) and mechanical ventilation before transplantation are increasing [2]. In 2018 , the proportion of lung transplant patients who received ECMO or mechanical ventilator support at the time of transplantation was $55.4 \%$, which was more than half of all transplantations performed in South Korea [1]. The preoperative condition of the waiting patient also affects the outcomes of surgery.

A large number of BDDs had not fulfilled the standard criteria for lung donation. Thus, many transplant programs had started to discuss and considered extended-criteria donors (ECD). Marginal donor or ECD is defined as an organ donor who does not completely satisfy the standard lung donor criteria, and the criteria differ slightly depending on published results or institution, but the ECDs are generally older, have more smoking history, and have lower $\mathrm{PaO}_{2} /$ fraction of $\mathrm{O}_{2}(\mathrm{P} / \mathrm{F})$ ratio than the ideal donor. ECDs showed no significant difference on the short-term outcome and long-term survival in most previous studies, but in some studies, smoking history of more than 20 packyears (PYR) showed decreases in the survival rate [3], and a $\mathrm{P} / \mathrm{F}$ ratio of $300 \mathrm{mmHg}$ or less increased the risk of $\mathrm{G} 3$ PGD at postoperative 48 hours [4]. Besides, since the characteristics of the recipients have a significant effect on the course of transplantation [5-7], it is also important to understand how these marginal donors affect the outcomes of high-risk recipients.

Our institution has been actively using ECD organs, and since 2014 , more than $25 \%$ of all lung transplants used ECD lungs every year. Thus, this study aimed to evaluate the immediate postoperative and long-term outcomes of lung transplantation in ECD lungs compared with standard-criteria donor (SCD) lungs. In addition, this study will discuss the safety of ECD lungs and appropriate indications of recipients using ECD lungs and investigate ways to increase the pool of organ donation, distribute it to appropriate recipients, and help in the proper distribution of limited donor organs.

\section{METHODS}

The retrospective study of patients' electronic data and the study protocol were approved by the Institutional Review Board of Severance Hospital (IRB No. 4-2020-0363). Informed consent was waived. This study was conducted in compliance with the principles of the Declaration of Helsinki.

\section{Description of Participants}

A total of 267 patients who had undergone double-lung transplantation from January 1, 2010, to May 31, 2019, were identified. Of these patients, 21 who received combined-organ transplantation, single-lung transplantation, and re-transplantation were excluded. Finally, 246 patients were enrolled in this study. Pre- and postoperative data for outcomes and survival data were analyzed. The SCD group included recipients with the following donor lung characteristics: age $<55$ years, $<20$ PYR smoking history, and P/F ratio $>300 \mathrm{mmHg}$. Recipients who received donor organs that do not fulfill these criteria were classified to the ECD group.

\section{Data Collection}

Data for analyses included recipient's age, sex, smoking status, pre-existing diseases, and preoperative mechanical support and donor's age, sex, smoking status, duration of mechanical ventilation, and organ size mismatch. A Ko- 
rean Network for Organ Sharing (KONOS) status 0 means that the recipients received ventilator support or ECMO support at the time of transplantation. Operative data including ischemic time and operation time were collected. Postoperative outcome data included weaning of ECMO in the operating room (OR), length of mechanical ventilation, and PGD 72 hours after surgery.

\section{Surgical Technique and Postoperative Management}

The surgical technique and postoperative management were the same as described in a previous study [8]. The surgical technique for transplantation was performed via a clamshell incision. In our hospital, since March 2013, peripheral veno-arterial ECMO via the right femoral vein and the right femoral artery was performed in all patients for cardiopulmonary support. The ECMO apparatus was inserted after gaining access to the intrathoracic space. Upon completion of anastomosis, reperfusion of the donor lung was performed with a delivered fraction of inspired oxygen $\left(\mathrm{FiO}_{2}\right)$ value of 0.2 , with mechanical ventilation. Patients with $\mathrm{P} / \mathrm{F}$ ratio $>200 \mathrm{mmHg}, \mathrm{ECMO}$, and stable hemodynamic status were weaned from ECMO in the OR after the transplantation procedure. If the $P / F$ ratio was less than $200 \mathrm{mmHg}$, the catheter was inserted into the right internal jugular vein, and the ECMO mode was changed to the veno-venous mode. After the graft function was stabilized, the patients were weaned from ECMO in the intensive care unit.

We performed routine fiberoptic bronchoscopy on the first day after surgery to implement pulmonary toileting and to evaluate bronchial anastomosis. Bacterial culture and Aspergillus antibody test of the bronchoalveolar lavage fluid obtained during bronchoscopy and weekly sputum cultures were also performed in these patients. All patients received triple immunosuppressive therapy consisting of mycophenolate mofetil, prednisone, and tacrolimus. Prophylactic regimens for Pneumocystis carinii (trimethoprim-sulfamethoxazole), fungi (itraconazole), and cytomegalovirus (valganciclovir) were initiated. Antibiotic therapy with fourth-generation cephalosporins (cefepime) and teicoplanin was initiated, with the dosing regimen adjusted on the basis of the results from the antibiotic sensitivity of cultures established from the perioperative samples. Based on our protocol, antibiotics were typically used for 2 weeks, unless the bacterial cultures tested positive, in which case antibiotics were used until the bacterial cultures tested negative.

\section{Statistical Analysis}

Statistical analyses were performed using IBM SPSS ver. 23 (IBM Corp., Armonk, NY, USA). Clinical parameters were described as mean \pm standard deviation for continuous variables, and some non-metric independent variables were described as median (interquartile range). Categorical variables were described as frequencies (\%) for categorical variables. Student t-test was used to compare continuous variables for parametric test and Mann-Whitney U-test for non-parametric test, and the chi-square test was used to compare categorical variables. Survival was calculated by the Kaplan-Meier method and compared with log-rank test. Cox proportional hazard model was used to identify risk factors with recipient age, recipient status at the time of transplantation, weaning from ECMO in the OR, G3 PGD at 72 Hours after transplantation, and donor group as covariates. Risk factors were significantly associated with survival at $\mathrm{P}<0.05$.

Table 1. Baseline characteristics of the donors and recipients

\begin{tabular}{lccr}
\hline \multicolumn{1}{c}{ Variable } & SCD $(\mathrm{n}=179)$ & ECD $(\mathrm{n}=67)$ & P-value \\
\hline Recipient age $(\mathrm{yr})$ & $50.46 \pm 13.35$ & $55.27 \pm 10.47$ & 0.004 \\
Age $>$ 65 years & $16(8.9)$ & $9(13.4)$ & 0.344 \\
Male sex & $108(60.3)$ & $40(59.7)$ & 0.928 \\
Status 0 & $60(33.5)$ & $29(32.6)$ & 0.156 \\
Disease entity & & & 0.108 \\
IPF & $96(53.6)$ & $37(55.2)$ & \\
CTD-ILD & $21(11.7)$ & $13(19.4)$ & \\
Bronchiectasis & $17(9.5)$ & $4(6.0)$ & \\
PAH & $8(4.5)$ & 0 & \\
BOS after BMT & $16(8.9)$ & $3(4.5)$ & \\
Emphysema & $1(0.6)$ & $3(4.5)$ & \\
LAM & $7(3.9)$ & $2(3.0)$ & \\
Others & $13(7.3)$ & $5(7.5)$ & \\
Donor age (yr) & $39.43 \pm 10.89$ & $51.03 \pm 10.38$ & $<0.001$ \\
Donor smoking Hx (PYR) & $8.02 \pm 5.73$ & $27.99 \pm 17.09$ & $<0.001$ \\
PF ratio & $470.72 \pm 80.25$ & $409.58 \pm 115.77$ & $<0.001$ \\
\hline
\end{tabular}

Values are presented as mean \pm standard deviation or number (\%).

SCD, standard-criteria donor; ECD, extended-criteria donor; IPF, idiopathic pulmonary fibrosis; CTD-ILD, connective tissue disease-associated interstitial lung disease; $\mathrm{PAH}$, pulmonary arterial hypertension; BOS, bronchiolitis obliterans syndrome; BMT, bone marrow transplantation; LAM, lymphangioleiomyomatosis; $\mathrm{Hx}$, history; PYR, pack-years; $\mathrm{P} / \mathrm{F}, \mathrm{PaO}_{2} /$ fraction of $\mathrm{O}_{2}$. 


\section{RESULTS}

The ECD and SCD groups were composed of 67 (27.2\%) and $179(72.8 \%)$ patients, respectively. In the ECD group, 31 donors $(46.3 \%)$ were $\geq 55$ years old, 26 donors (38.8\%) had a smoking history $>20$ PYR, and 17 donors $(25.4 \%)$ had $\mathrm{P} / \mathrm{F}$ ratio $<300 \mathrm{mmHg}$. Donor and recipient characteristics in each group are described in Table 1 and postoperative outcomes are shown in Table 2. The recipients were significantly younger $(50.46 \pm 13.35$ vs. $55.27 \pm 10.47, \mathrm{P}=0.004)$ and the rate of ECMO weaning in the OR was significantly

Table 2. Postoperative outcomes

\begin{tabular}{|c|c|c|c|}
\hline Variable & $\operatorname{SCD}(n=179)$ & $\operatorname{ECD}(n=67)$ & P-value \\
\hline Ischemic time (min) & $329.00 \pm 79.42$ & $326.79 \pm 78.53$ & 0.846 \\
\hline ECMO weaning at $\mathrm{OR}$ & $90(61.2)(n=147)$ & $28(45.2)(n=62)$ & 0.047 \\
\hline PGD G3 after 72 hours & $31(18.6)$ & $17(28.3)$ & 0.140 \\
\hline Hemodialysis & $37(20.7)$ & $15(22.4)$ & 0.861 \\
\hline Tracheostomy & $40(22.3)$ & $18(26.9)$ & 0.501 \\
\hline $\begin{array}{l}\text { Length of mechanical } \\
\text { ventilation (day) }\end{array}$ & $4 \pm 8$ & $3 \pm 7$ & 0.349 \\
\hline $\begin{array}{l}\text { Length of hospital } \\
\text { stay (day) }\end{array}$ & $32.0 \pm 31$ & $30.0 \pm 33$ & 0.385 \\
\hline Operative mortality & $38(21.2)$ & $14(20.9)$ & 0.955 \\
\hline $\begin{array}{l}\text { Postoperative 1-year FVC } \\
\text { (\% predicted) }\end{array}$ & $73 \pm 24.5$ & $78.0 \pm 45.5$ & 0.624 \\
\hline $\begin{array}{l}\text { Postoperative 1-year FEV1 } \\
\text { (\% predicted) }\end{array}$ & $66.5 \pm 21.75$ & $67.0 \pm 35$ & 0.626 \\
\hline
\end{tabular}

Values are presented as mean \pm standard deviation or number (\%).

SCD, standard-criteria donor; ECD, extended-criteria donor; ECMO, extracorporeal membrane oxygenation; $\mathrm{OR}$, operating room; PGD, primary graft dysfunction; FVC, forced vital capacity; FEV1, forced expiratory volume in 1 second. higher $(61.2 \%$ vs. $45.2 \%, \mathrm{P}=0.047)$ in the SCD group than in the ECD group. Other preoperative characteristics and operative outcomes were not significantly different between the two groups.

In the logistic regression model, ECD was significantly associated with risk for failure of ECMO weaning in the OR (hazard ratio [HR], 0.522; 95\% confidence interval [Cl], 0.286-0.951; $P=0.034)$, but ECD was not associated with risk of G3 PGD at 72 hours after transplantation in the univariate analysis $(\mathrm{HR}, 1.734 ; 95 \% \mathrm{Cl}, 0.875-3.436 ; \mathrm{P}=0.114)$. In the multivariate analysis, ECD also showed significant association with risk for failure of ECMO weaning in the OR (HR, 0.531; 95\% Cl, 0.291-0.970; $\mathrm{P}=0.039)$ but no association with risk of G3 PGD at 72 hours after transplantation (HR, 1.652; 95\% Cl, 0.827-3.302; $P=0.155)$ considering recipient's age and status at operation (Table 3 ).

Overall survival rate of ECD was not significantly different (3-year survival rate, $60.4 \%$ vs. $43.8 \% ; P=0.120$ ) (Fig. 1) from that of SCD. The ECD group showed comparable survival rate with the SCD group (HR, 1.413; $95 \% \mathrm{Cl}, 0.885-$ 2.255; $\mathrm{P}=0.148$ ) (Table 4), with adjustment for recipient age, recipient status at transplantation, ECMO weaning in the OR, and G3 PGD 72 hours after transplantation. However, when the recipient had KONOS status 0 at the time of transplantation (HR, 1.622; 95\% Cl, 1.025-2.568; $\mathrm{P}=0.039$ ), G3 PGD at 72 hours after surgery $(\mathrm{HR}, 2.508 ; 95 \% \mathrm{Cl}$, 1.416-4.440; $\mathrm{P}=0.002$ ) was a risk factor that decreased survival (Table 4).

A subgroup analysis was performed to confirm the effect of ECD according to recipient factor which affected survival rate in the hazard model. The survival of the ECD and SCD groups was compared by dividing the age of the recipients into $>65$ years and $\leq 65$ years. The ECD group tended to have lower survival rate than the SCD group,

Table 3. Risk analysis for ECMO weaning at the OR and PGD G3 72 hours after operation

\begin{tabular}{|c|c|c|c|c|c|c|}
\hline \multirow{2}{*}{ Variable } & \multicolumn{3}{|c|}{ Univariate } & \multicolumn{3}{|c|}{ Multivariate } \\
\hline & HR & $95 \% \mathrm{Cl}$ & P-value & $\mathrm{HR}$ & $95 \% \mathrm{Cl}$ & P-value \\
\hline \multicolumn{7}{|c|}{ ECMO weaning at $\mathrm{OR}$} \\
\hline R_age $>65$ years & 0.900 & $0.383-2.115$ & 0.810 & 0.913 & $0.384-2.171$ & 0.837 \\
\hline R_status 0 & 0.748 & $0.425-1.318$ & 0.316 & 0.774 & $0.437-1.374$ & 0.382 \\
\hline ECD & 0.522 & $0.286-0.951$ & 0.034 & 0.531 & $0.291-0.970$ & 0.039 \\
\hline \multicolumn{7}{|c|}{ PGD G3 after 72 hours } \\
\hline R_age $>65$ years & 1.021 & $0.361-2.892$ & 0.968 & 1.092 & $0.379-3.147$ & 0.870 \\
\hline R_status 0 & 1.859 & $0.970-3.559$ & 0.062 & 1.789 & $0.929-3.444$ & 0.082 \\
\hline ECD & 1.734 & $0.875-3.436$ & 0.114 & 1.652 & $0.827-3.302$ & 0.155 \\
\hline
\end{tabular}

ECMO, extracorporeal membrane oxygenation; OR, operating room; PGD, primary graft dysfunction; HR, hazard ratio; Cl, confidence interval; $\mathrm{R}_{-}$age, recipient age; R_status 0, recipient Korean Network for Organ Sharing status 0 at the time of operation; ECD, extended-criteria donor. 
but no significant difference in survival rate was found between the ECD and SCD groups when the recipient was $\leq 65$ years old (Fig. 2). Second, the survival rates of the ECD and SCD groups were compared by dividing patients whether they have KONOS status 0 or not at the time of

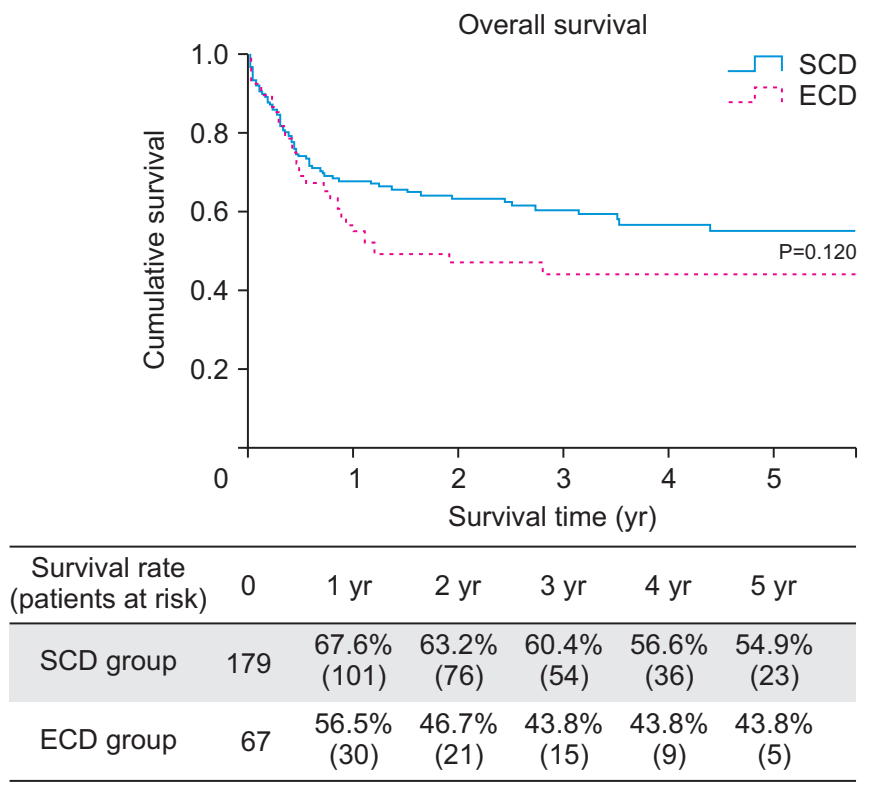

Fig. 1. Overall survival. SCD, standard-criteria donor; ECD, extended-criteria donor. transplantation. No significant difference was found in the survival rate between the ECD and SCD groups according to recipient status, but when the recipient had KONOS status 0 , both ECD and SCD groups had significantly lower survival rate than patients who had no KONOS status 0 from SCD (Fig. 3).

\section{DISCUSSION}

This study was conducted to determine the feasibility of ECD lungs and the appropriate usage of ECD lungs. We

Table 4. Risk analysis for overall survival

\begin{tabular}{lccc}
\hline \multicolumn{1}{c}{ Variable } & \multicolumn{3}{c}{ Multivariate } \\
\cline { 2 - 4 } & HR & $95 \% \mathrm{Cl}$ & P-value \\
\hline R_age $>65 \mathrm{yr}$ & 1.565 & $0.848-2.887$ & 0.152 \\
R_status 0 & 1.622 & $1.025-2.568$ & 0.039 \\
ECD & 1.413 & $0.885-2.255$ & 0.148 \\
ECM0 weaning at OR & 0.952 & $0.552-1.644$ & 0.861 \\
PGD G3 after 72 hours & 2.508 & $1.416-4.440$ & 0.002
\end{tabular}

$\mathrm{HR}$, hazard ratio; $\mathrm{Cl}$, confidence interval; R_age, recipient age; R_status 0 , recipient Korean Network for Organ Sharing status 0 at the time of operation; ECD, extended-criteria donor; ECMO, extracorporeal membrane oxygenation; OR, operating room; PGD, primary graft dysfunction.

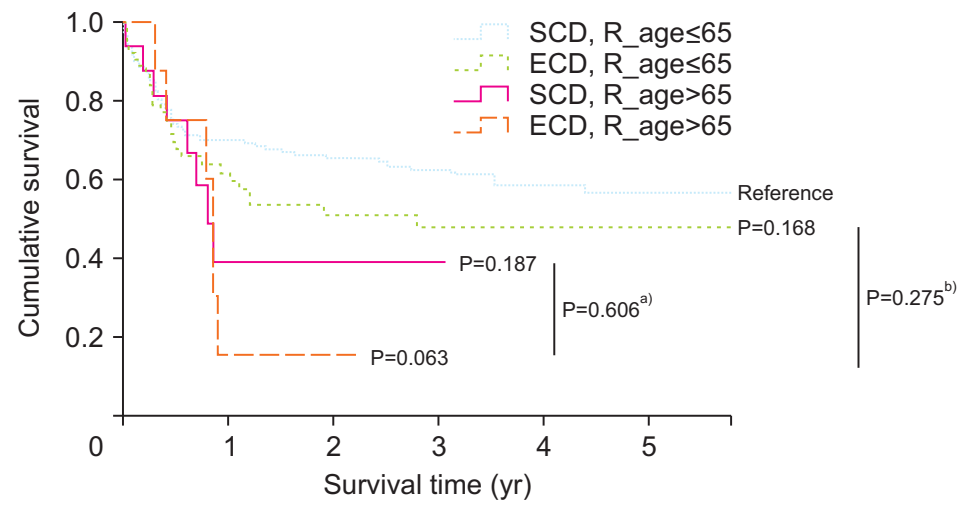

\begin{tabular}{lcccccc}
\hline $\begin{array}{c}\text { Survival rate } \\
\text { (patients at risk) }\end{array}$ & 0 & $1 \mathrm{yr}$ & $2 \mathrm{yr}$ & $3 \mathrm{yr}$ & $4 \mathrm{yr}$ & $5 \mathrm{yr}$ \\
\hline $\mathrm{SCD}, \leq 65 \mathrm{yrs}$ & 163 & $\begin{array}{c}69.8 \% \\
(97)\end{array}$ & $\begin{array}{c}65.1 \% \\
(74)\end{array}$ & $\begin{array}{c}62.1 \% \\
(53)\end{array}$ & $\begin{array}{c}58.2 \% \\
(36)\end{array}$ & $\begin{array}{c}56.5 \% \\
(23)\end{array}$ \\
ECD, $\leq 65 \mathrm{yrs}$ & 58 & $\begin{array}{c}61.8 \% \\
(39)\end{array}$ & $\begin{array}{c}50.7 \% \\
(21)\end{array}$ & $\begin{array}{c}47.5 \% \\
(15)\end{array}$ & $\begin{array}{c}47.5 \% \\
(9)\end{array}$ & $\begin{array}{c}47.5 \% \\
(6)\end{array}$ \\
$\mathrm{SCD},>65 \mathrm{yrs}$ & 16 & $\begin{array}{c}38.9 \% \\
(4)\end{array}$ & $\begin{array}{c}38.9 \% \\
(2)\end{array}$ & $\begin{array}{c}38.9 \% \\
(1)\end{array}$ & - & - \\
$\mathrm{ECD},>65 \mathrm{yrs}$ & 9 & $\begin{array}{c}15.0 \% \\
(1)\end{array}$ & $\begin{array}{c}15.0 \% \\
(1)\end{array}$ & - & - & - \\
\hline
\end{tabular}

Fig. 2. Survival rate according to recipients aged $>65$ years and donor group. $R_{-}$ age, recipient age. ${ }^{a)}$ P-value between the standard-criteria donor (SCD) group and extended-criteria donor (ECD) group among recipients aged $>65$ years; ${ }^{\text {b) }} \mathrm{P}$-value between recipients aged $>65$ years and $>65$ years in the ECD group. 


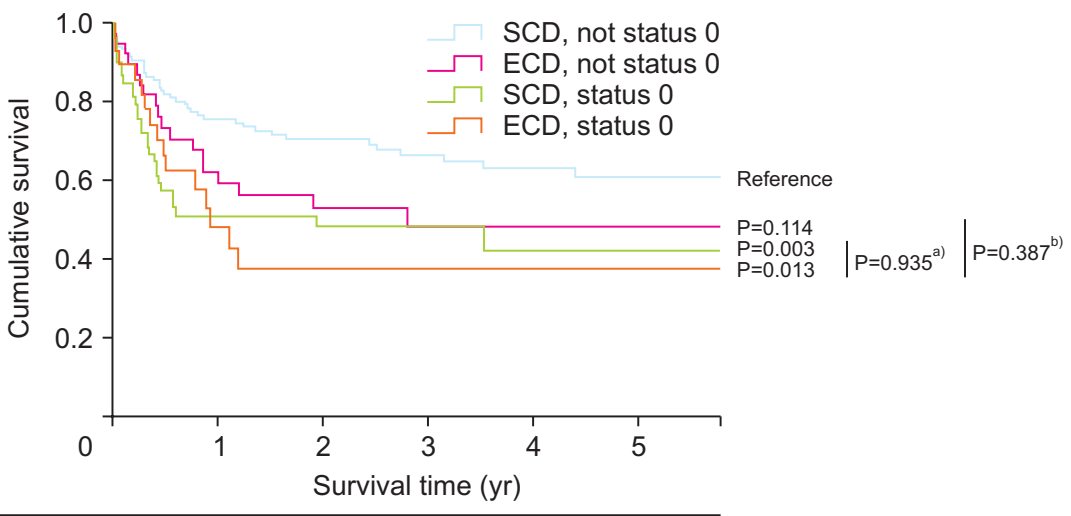

\begin{tabular}{ccccccc}
\hline $\begin{array}{c}\text { Survival rate } \\
\text { (patients at risk) }\end{array}$ & 0 & $1 \mathrm{yr}$ & $2 \mathrm{yr}$ & $3 \mathrm{yr}$ & $4 \mathrm{yr}$ & $5 \mathrm{yr}$ \\
\hline $\begin{array}{c}\text { SCD, } \\
\text { not status 0 }\end{array}$ & 119 & $\begin{array}{c}75.6 \% \\
(79)\end{array}$ & $\begin{array}{c}70.5 \% \\
(60)\end{array}$ & $\begin{array}{c}66.5 \% \\
(45)\end{array}$ & $\begin{array}{c}63.2 \% \\
(30)\end{array}$ & $\begin{array}{c}60.9 \% \\
(18)\end{array}$ \\
ECD, & 38 & $\begin{array}{c}61.9 \% \\
(21)\end{array}$ & $\begin{array}{c}52.7 \% \\
(16)\end{array}$ & $\begin{array}{c}47.9 \% \\
(10)\end{array}$ & $\begin{array}{c}47.9 \% \\
(6)\end{array}$ & $\begin{array}{c}47.9 \% \\
(4)\end{array}$ \\
not status 0 & & $\begin{array}{c}50.9 \% \\
(22)\end{array}$ & $\begin{array}{c}48.0 \% \\
(16)\end{array}$ & $\begin{array}{c}48.0 \% \\
(11)\end{array}$ & $\begin{array}{c}42.0 \% \\
(6)\end{array}$ & $\begin{array}{c}42.0 \% \\
(5)\end{array}$ \\
SCD, status 0 & 60 & $\begin{array}{c}48.1 \% \\
(9)\end{array}$ & $\begin{array}{c}37.4 \% \\
(5)\end{array}$ & $\begin{array}{c}37.4 \% \\
(5)\end{array}$ & $\begin{array}{c}37.4 \% \\
(3)\end{array}$ & $\begin{array}{c}37.4 \% \\
(2)\end{array}$ \\
\hline ECD, status 0 & 29 & & & & \\
\hline
\end{tabular}

Fig. 3. Survival rate according to recipients with Korean Network for Organ Sharing (KONOS) status 0 at transplantation and donor group. ${ }^{\text {a) }}$ P-value between the standard-criteria donor (SCD) group and extended-criteria donor (ECD) group of recipients with status 0 at transplantation; ${ }^{b} \mathrm{P}$-value between recipients with status 0 at transplantation and no status 0 at transplantation in the ECD group.

found no significant differences in early postoperative outcomes including length of mechanical ventilation and length of hospital stay between the ECD and SCD groups. In the risk analysis, ECD lungs affected ECMO weaning in the OR but not G3 PGD at 72 hours after transplantation. As regards overall survival, no significant difference was found between the two groups, but it was significantly low in recipients with KONOS status 0 at transplantation; moreover, it tended to be worse in the ECD group.

After the emergence of the ECD concept, the proportion of ECD in transplanted lungs has increased. The definition of ECD differs slightly depending on the institution or study, but most are based on age, smoking history, and P/ $F$ ratio. According to Yeo et al. [9], more than $60 \%$ of BDD lungs used in Korea from 2012 to 2016 were categorized as ECD. In our study, the proportion of recipients who had received ECD lungs was $26.6 \%$, and when divided by year, the use of ECD lungs increased from 2012 and gradually increased since then, showing a rate approximately $30 \%$ in recent years (Supplementary Table 1). Lungs from BDDs have a lower procurement rate than other organs. In Korea, the lung utility rate of BDDs was $20.5 \%$ in 2018 , which was higher than the previous rate of less than $20 \%$, but is still less than half compared with that of other thoracic organs, such as the heart. According to Yeo et al. [9], 74\% of all BDDs in Korea were not evaluated for lung transplantation,

$82(8 \%)$ of which were SCD and 337 (33\%) were ECD.

There were several previous studies of older donors. According to some studies, organs from donors aged 5564 years did not affect short-term and long-term outcomes $[10,11]$; however, donors aged $>65$ years showed slightly decreased long-term outcome [11]. On the contrary, Schultz et al. showed lower chronic lung allograft dysfunction (CLAD)-free survival in donors aged $\geq 55$ years [12]. Moreover, Hayes et al. [13] used United Network for Organ Sharing (UNOS) data and showed that organs from older donors did not affect outcomes of recipients aged $\geq 50$ years, but younger recipients showed limited outcomes. Some studies reported about the effect of donor smoking history on posttransplant outcomes. Based on UNOS data, Reyes et al. [3] had shown that organs from donors with smoking history $>20$ PYR appeared to have slightly worse longterm survival with a not powerful effect. Schultz et al. [12] reported that current or former smokers have decreased overall survival but have no influence on CLAD-free survival after transplantation. In terms of $\mathrm{PaO}_{2}$, Zych et al. [4] had shown that the rate of G3 PGD at 48 hours after transplantation was significantly higher in donors with $\mathrm{P} / \mathrm{F}$ ratio $<300 \mathrm{mmHg}$, and other early and late outcomes had no difference [4]. In addition, Reyes et al. [3] had shown that survival is not inferior in lungs with $\mathrm{P} / \mathrm{F}$ ratio as low as 230 $\mathrm{mmHg}$. 
In our study, the characteristics of recipients rather than the characteristics of donors had influenced the posttransplantation outcome. G3 PGD at 72 hours after transplantation and preoperative recipient of status 0 were found to be significant risk factors to decreased survival. Other previous studies presented that recipients' characteristics determined the outcomes of transplantation. Pretransplantation mechanical ventilation has been associated with posttransplantation mortality [6]. The Toronto group reported that the 30 -day mortality rate was higher in "non-guideline" recipients than in "guideline" recipients of ECD lungs [14]. Sommer et al. [5] also studied outcomes of ECD lungs according to the allocation of recipients, and they showed that marginal-donor lungs for stable recipients were acceptable. In a previous study based on UNOS data, patients who received ECD lungs had low survival rate; especially, those with lung allocation score $\geq 70$ who received ECD have the lowest survival rate [15].

This study has some limitations. First, given the single institutional setting and retrospective design, the results of this study cannot represent all outcomes of ECD. Second, because factors constituting the ECD are not considered separately, identifying the detailed risk for each factor is difficult. Third, patients' long-term outcomes were compared only with simple survival, and the outcomes of ECD such as quality of life were not qualitatively compared.

In conclusion, the outcome of ECD is not inferior to that of SCD. However, recipient characteristics such as age and KONOS status at the time of operation are thought to have a more important effect on patient's outcome. Therefore, ECD lung should be considered a potential donor organ following active donor management rather than a contraindication of transplantation in highly selected recipients.

\section{ACKNOWLEDGMENTS}

\section{Conflict of Interest}

No potential conflict of interest relevant to this article was reported.

\section{ORCID}

Jee Won Suh

Jin Gu Lee

Moo Suk Park

Song Yee Kim

Su Jin Jeong https://orcid.org/0000-0003-0287-0651 https://orcid.org/0000-0003-2767-6505 https://orcid.org/0000-0003-0820-7615 https://orcid.org/0000-0001-8627-486X https://orcid.org/0000-0003-4025-4542
Hyo Chae Paik

https://orcid.org/0000-0001-9309-8235

\section{Author Contributions}

Conceptualization: HCP, JWS. Data curation: HCP, JWS, JGL, MSP, SYK, SJJ. Formal analysis: JWS. Investigation: HCP, JWS. Methodology: JWS, JGL, MSP, SYK, SJJ. Visualization: JWS. Writing-original draft: JWS. Writing-review \& editing: HCP.

\section{Supplementary Materials}

Supplementary materials can be found via https://doi. org/10.4285/kjt.2020.34.3.185.

\section{REFERENCES}

1. Korean Network for Organ Sharing (KONOS). 2018 Annual data report, in Korean Network for Organ Sharing [Internet]. Seoul: KONOS; 2018 [cited 2020 Aug 20]. Available from: https://www.konos.go.kr/konosis/common/bizlogic.jsp.

2. Neizer H, Singh GB, Gupta S, Singh SK. Addressing donor-organ shortages using extended criteria in lung transplantation. Ann Cardiothorac Surg 2020;9:49-50.

3. Reyes KG, Mason DP, Thuita L, Nowicki ER, Murthy SC, Pettersson GB, et al. Guidelines for donor lung selection: time for revision? Ann Thorac Surg 2010;89:175664.

4. Zych B, García Sáez D, Sabashnikov A, De Robertis F, Amrani $\mathrm{M}$, Bahrami $\mathrm{T}$, et al. Lung transplantation from donors outside standard acceptability criteria: are they really marginal? Transpl Int 2014;27:1183-91.

5. Sommer W, Kühn C, Tudorache I, Avsar M, Gottlieb J, Boethig $D$, et al. Extended criteria donor lungs and clinical outcome: results of an alternative allocation algorithm. J Heart Lung Transplant 2013;32:1065-72.

6. Moreno P, Alvarez A, Santos F, Vaquero JM, Baamonde $\mathrm{C}$, Redel $\mathrm{J}$, et al. Extended recipients but not extended donors are associated with poor outcomes following lung transplantation. Eur $\mathrm{J}$ Cardiothorac Surg 2014;45:1040-7.

7. Sommer W, lus F, Salman J, Avsar M, Tudorache I, Kühn $C$, et al. Survival and spirometry outcomes after lung transplantation from donors aged 70 years and older. J Heart Lung Transplant 2015;34:1325-33.

8. Suh JW, Lee JG, Jeong SJ, Park MS, Kim SY, Paik HC. Risk of bronchial dehiscence in lung transplant recip- 
ients with carbapenemase-producing klebsiella. Ann Thorac Surg 2020;110:265-71.

9. Yeo HJ, Yoon SH, Lee SE, Jeon D, Kim YS, Cho WH, et al. Current status and future of lung donation in Korea. J Korean Med Sci 2017;32:1953-8.

10. Dahlman S, Jeppsson A, Scherstén H, Nilsson F. Expanding the donor pool: lung transplantation with donors 55 years and older. Transplant Proc 2006;38:26913.

11. Bittle GJ, Sanchez PG, Kon ZN, Claire Watkins A, Rajagopal K, Pierson RN 3rd, et al. The use of lung donors older than 55 years: a review of the United Network of Organ Sharing database. J Heart Lung Transplant 2013;32:760-8.

12. Schultz HH, Møller $\mathrm{CH}$, Zemtsovski M, Ravn J, Perch
$\mathrm{M}$, Martinussen $\mathrm{T}$, et al. Donor smoking and older age increases morbidity and mortality after lung transplantation. Transplant Proc 2017;49:2161-8.

13. Hayes D Jr, Black SM, Tobias JD, Higgins RS, Whitson BA. Influence of donor and recipient age in lung transplantation. J Heart Lung Transplant 2015;34:43-9.

14. Pierre AF, Sekine $Y$, Hutcheon MA, Waddell TK, Keshavjee SH. Marginal donor lungs: a reassessment. J Thorac Cardiovasc Surg 2002;123:421-7.

15. Mulligan MJ, Sanchez PG, Evans CF, Wang Y, Kon ZN, Rajagopal $\mathrm{K}$, et al. The use of extended criteria donors decreases one-year survival in high-risk lung recipients: a review of the United Network of Organ Sharing Database. J Thorac Cardiovasc Surg 2016;152:891-8. 